\title{
ПУТИ ДОСТИЖЕНИЯ ОПТИМАЛЬНОГО СООТВЕТСТВИЯ СТРУКТУРЫ УПРАВЛЕНИЯ НАУКОЕМКИМ ПРЕДПРИЯТИЕМ ИННОВАЦИОННЫМ ЗАДАЧАМ
}

(c) 2019 Чудесова Галина Павловна

доктор экономических наук, профессор

Университет ИТМО, Россия, Санкт-Петербург

(c) 2019 Валиев Андрей Маратович

магистрант второго курса факультета технологического менеджмента и инноваций

Университет ИТМО, Россия, Санкт-Петербург

(c) 2019 Осипова Мария Валерьевна

магистрант второго курса факультета технологического менеджмента и инноваций

Университет ИТМО, Россия, Санкт-Петербург

(c) 2019 Отсолайнен Александр Артемьевич

магистрант второго курса факультета технологического менеджмента и инноваций

Университет ИТМО, Россия, Санкт-Петербург

(c) 2019 Хаванова Дарья Алексеевна

магистрант второго курса факультета технологического менеджмента и инноваций

Университет ИТМО, Россия, Санкт-Петербург

(c) 2019 Черепанова Анастасия Евгеньевна

магистрант второго курса факультета технологического менеджмента и инноваций

Университет ИТМО, Россия, Санкт-Петербург

В данной статье рассматриваются структуры организационного управления, а также инновационные задачи. Определены виды структур организационного управления и круг инновационных задач в рамках Российской Федерации. Особое внимание уделяется критериям оптимального соответствия структур управления инновационным задачам. В заключении сформированы пути достижения соответствия между инновационными задачами и структурами управления.

Ключевые слова: структура, задачи, управление, критерии.

Актуальность темы исследования связана с тем, что за период с 2016 по 2018 годы Российская Федерация все больше теряет позиции в рейтинге Глобального индекса инноваций (The Global Innovation Index), что отражает факт снижения эффективности, по моему мнению, связанный с неэффективным и некачественным управлением инновационными предприятиями. В определенной степени это связано с высоким уровнем бюрократизации в современной России, что приводит к следующему выводу - структуры управления инновационными предприятиями не соответствуют решаемым ими задачам.

Объектом исследования является структуры организационного управления и инновационные задачи.

Предметом исследования выступают критерии соответствия между структурами организа- ционного управления и инновационными задачами.

Цель исследования - попытаться сформулировать критерии соответствия между структурами организационного управления и инновационными задачами.

Для реализации данной цели необходимо решение следующих задач:

- охарактеризовать основные виды структур управления с точки зрения поставленной цели;

- определить круг инновационных задач применительно к Российской Федерации;

- сформулировать критерии соответствия.

В работе использованы общенаучные методы: теоретический анализ, метод сравнения и обобщения.

Информационную базу исследования со- 
ставили материалы специализированных Интернет-сайтов, данные периодической печати, материалы научно-практических конференций.

Результаты исследования представляют теоретический и практический интерес. Материалы теоретического исследования могут быть полезны при подготовке лекций по предметам «Управление персоналом», «Организационное поведение» и т.д.

Виды структур организационного управления и инновационных задач

Организационная структура управления логические соотношения уровней управления и функциональных областей, организованные таким образом, чтобы обеспечить эффективное достижение целей. [5, с. 486]

Организационная структура управления направлена на установление четких взаимосвязей между отдельными подразделениями организации, распределение между ними прав и ответственности.

Рассмотрим основные виды организационных структур управления:

1) Линейная структура управления - это структура образуется в результате построения аппарата управления только из взаимоподчиненных органов в виде иерархической лестницы (рис. 1) [3, с. 23].

2) Линейно-штабная структура - в отличие от линейной включает в себя специально созданные при линейных руководителях подразделения, которые не обладают правом принятия решений и руководства каким-либо нижестоящим подразделением (рис. 2) [3, с. 24].

3) Функциональная структура предполагает, что каждый орган управления специализирован на выполнении отдельных функций на всех уровнях управления (рис. 3) [3, с. 24]. Выполнение указаний каждого функционального органа в пределах его компетенции обязательно для производственных подразделений. Решения по общим вопросам принимаются коллегиально:

4) Разновидностью функциональной структуры является линейно-функциональная структура (рис. 4) [3, с. 25]. При линейнофункциональной структуре линейные звенья управления призваны командовать, а функциональные - консультировать, помогать в разработке конкретных вопросов и подготовке соответствующих решений, программ, планов:

5) Дивизионная структура управления при такой структуре на предприятиях создают-

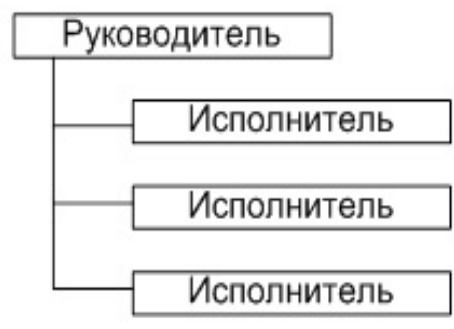

Простая линейная структура

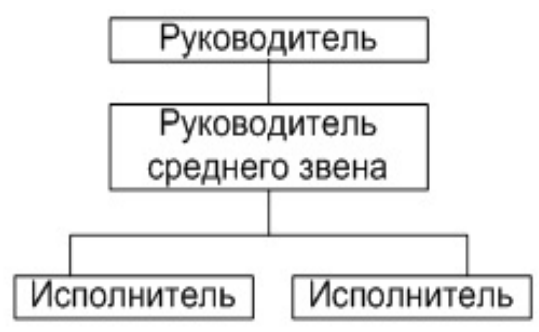

Сложная линейная структура

Puc. 1. Линейная структура управления

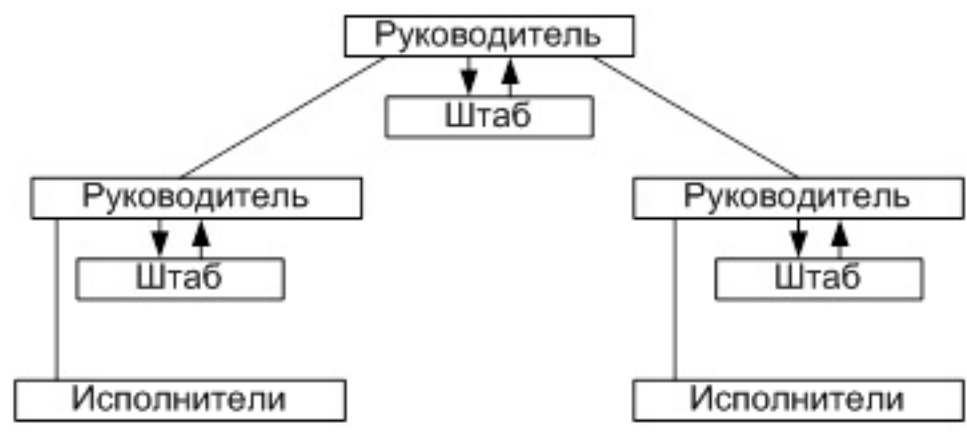

Puc. 2. Линейно-штабная структура управления 


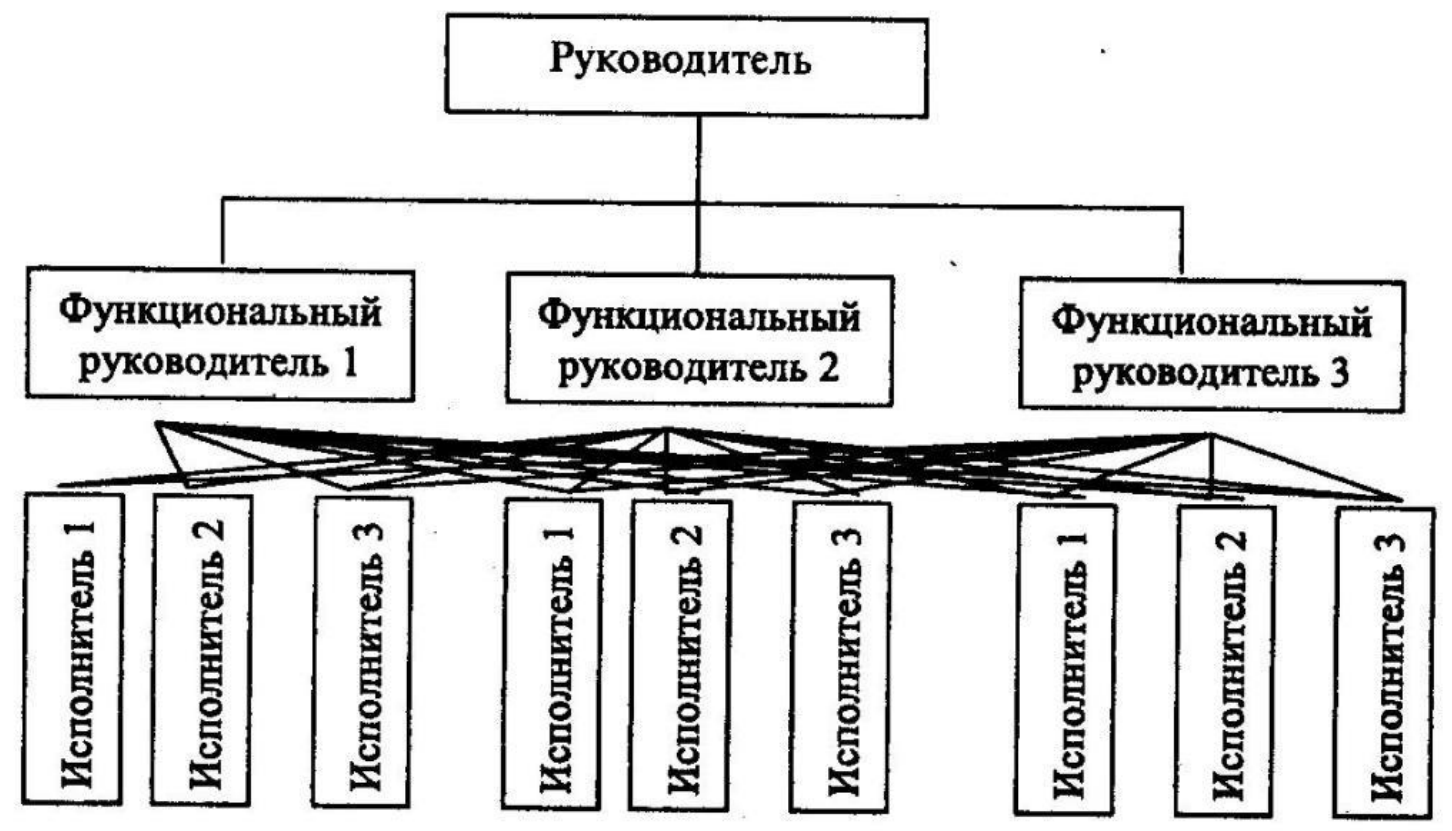

Puc. 3. Функциональная структура управления

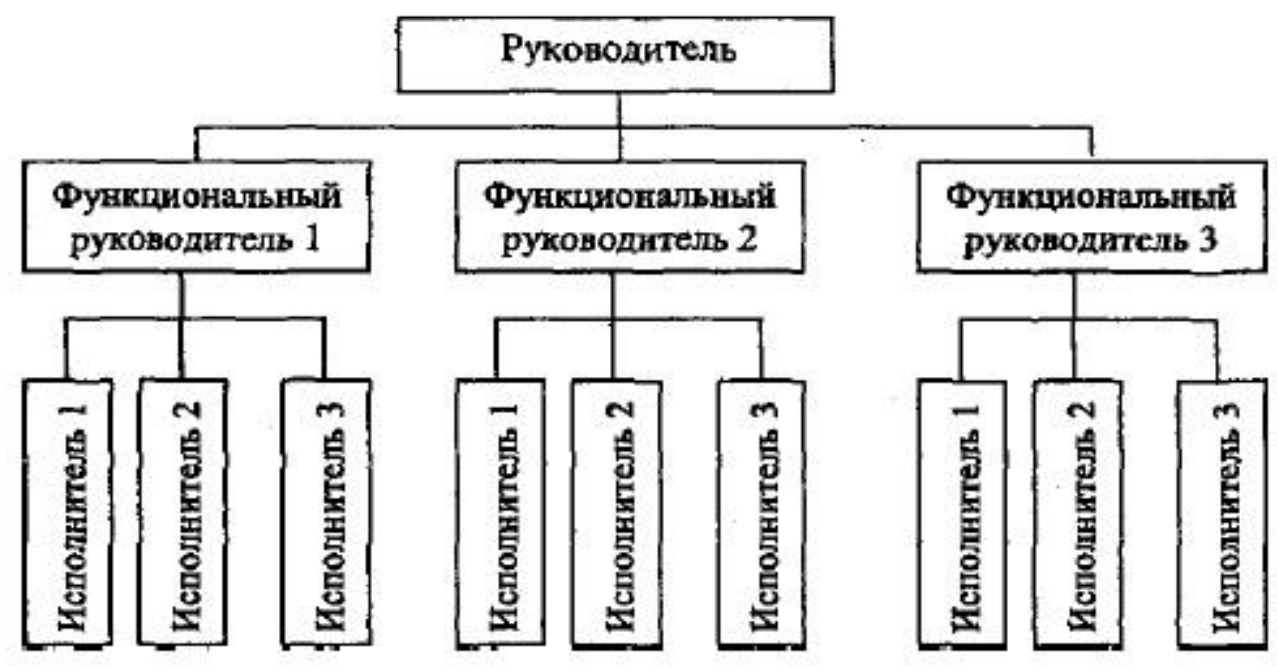

Puc. 4. Линейно-функциональная структура управления

ся производственные отделы, которым предоставляется определенная самостоятельность в осуществлении оперативной деятельности (рис. 5) $[3$, c. 26].

6) Матричная структура - это структура, в которой действует принцип двойного подчинения исполнителей: с одной стороны - непосредственному руководителю функциональной службы, с другой стороны - руководителю проекта, который наделен необходимыми полномочиями в соответствии с запланированными сроками выполнения данного проекта (рис. 6) [3, c. 27].
Теперь необходимо сформулировать основные инновационные задачи:

1) Проведение научно-исследовательских и опытно - конструкторских работ;

2) Производство и реализация новых продуктов и изделий;

3) Поиск новых технологий, ноу-хау и создание на их основе технологического процесса производства новой продукции;

4) Организация опытного производства и освоение новшеств;

5) Подготовка, обучение, переквалификация и подбор персонала. 


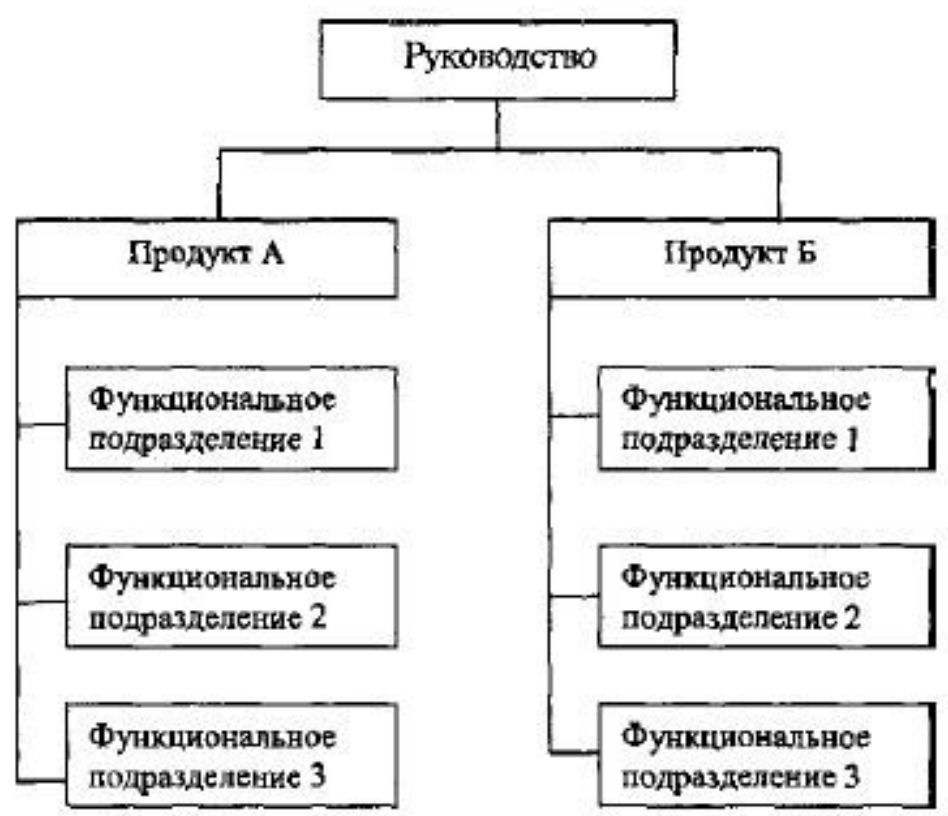

Puc. 5. Дивизионная структура управления

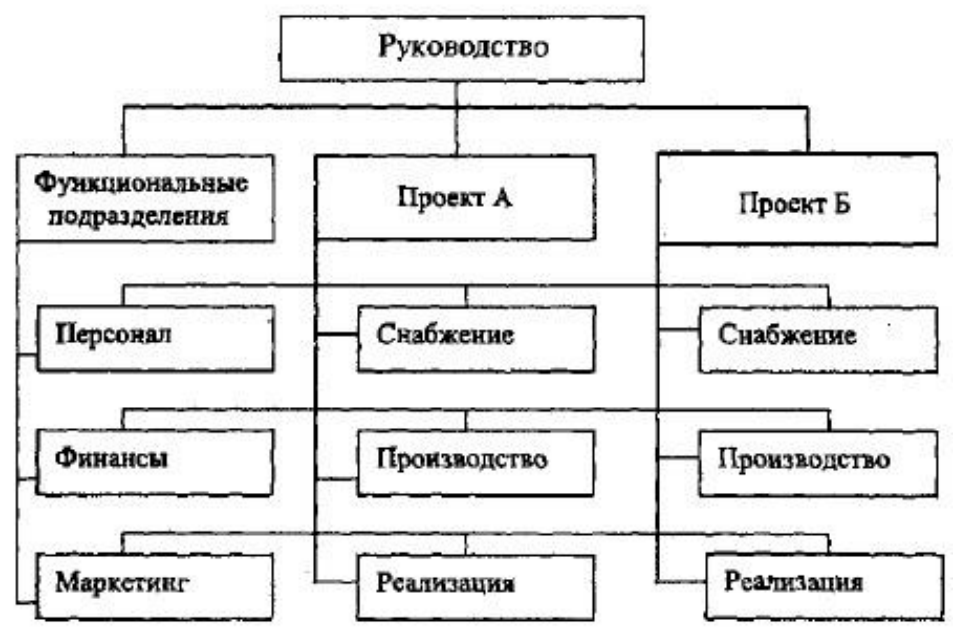

Puc. 6. Матричная структура управления

Критерии оптимального соответствия структур управления инновационным задачам

После того, как были сформулированы основные инновационные задачи предприятия и виды организационных структур управления, можно перейти к формулировке критериев оптимального их соответствия инновационным задачам.

Первым и одним из самых важных критериев я считаю «скорость принятия решения в организации». Очень часто при решении любых задач, в том числе инновационных, исполните- ли встречают множество бюрократических препятствий на пути к их решению.

В процессе анализа структур управления скорость принятия решения будет оцениваться в баллах от 1 до 3, где:

1 - это длительная процедура принятия решения;

2 - это средняя длительность принятия решения;

3 - это быстрое принятие решения.

Такая же бальная методика оценивания будет относиться и к последующим критериям, сформулированным в рамках данной работы. 
Следующим критерием соответствия является «количество затрачиваемых человеческих ресурсов на решение одной задачи». Конечно, задачи бывают различными, и требуют разного количества ресурсов для своего решения. Данный критерий позволяет подбирать структуру управления в зависимости от имеющихся ресурсов. В рамках данного критерия предлагаются следующие значения:

1 - на решение задачи тратится большое число человеческих ресурсов;

2 - на решение задачи тратится среднее количество человеческих ресурсов;

3 - на решение задачи тратится минимальное количество человеческих ресурсов.

Третий критерий звучит как «гибкость и взаимозаменяемость». Этот критерий позволяет понять насколько организационная структура готова к изменениям и воздействию внешних факторов, например, насколько структура готова к уходу одного из ключевых сотрудников.

В контексте данного критерия применяются следующие оценки:

1 - Система не гибкая, тяжело реагирует на изменения;

2 - Система относительно гибкая, может реагировать на изменения;

3 - Система гибкая, быстро реагирует на изменения.

Для следующего критерия предлагается взять за основу «степень децентрализации» [2, 7]. В решении многих инновационных задач большую роль играет автономность подразделений и возможность самим принимать решения, что хорошо сказывается на скорости выполнения задач. Например, для завершения опытного образца не хватает резисторов, которые стоят 250-500 рублей, разработчик вполне может сам купить их в магазине и потом сдать товарный чек. Однако если высок уровень централизации, то возможно из-за такой мелочи вся работа затянется на недели.

Предлагаются следующие оценки:

1 - Система централизована, все решения сосредоточены на высшем уровне управления;

2 - Система относительно децентрализована, возможно принятие простых решений на нижнем уровне управления;

3 - Система децентрализована, решения принимаются руководителем, который ближе всего к проблеме.

Последним критерием является «Преоблада- ние горизонтальных потоков информации над вертикальными». Суть данного критерия состоит в том, что взаимодействие подразделений будет максимально эффективным, если они будут решать смежные вопросы напрямую. В то же время в некоторых структурах взаимодействие может происходить только через высшее руководство организации.

Для данного критерия характерны следующие оценки:

1 - Преобладают вертикальные потоки информации, где все взаимодействие проходит через высшее руководство;

2 - Вертикальные потоки информации сбалансированы, простые взаимодействия происходят без участия высшего руководства;

3 - Преобладают горизонтальные потоки информации, подразделения только в крайнем случае обращаются к руководству в рамках взаимодействия.

Итак, нами были сформированы 5 основных критериев оптимального соответствия структур управления инновационным задачам:

1) Скорость принятия решения;

2) Кол-во затрачиваемых человеческих ресурсов для решения одной задачи;

3) Гибкость и взаимозаменяемость;

4) Степень децентрализации;

5) Преобладание горизонтальных потоков информации над вертикальными.

Предлагается следующий алгоритм формирования организационной структуры:

- Для каждой конкретной задачи выбираются два наиболее важных критерия;

- Затем после проведения анализа структур управления выявляются системы с наивысшим общим значением по выбранным критериям;

- После первого отсева из оставшихся при равном значении основных показателей определяется структура, набравшая большее число баллов по остальным критериям.

Балльно-рейтинговая таблица показана в таблице 1.

Так, например, для решения задач проведения научно-исследовательских и опытно - конструкторских работ основными критериями, очевидно, являются «степень децентрализации» и «преобладание горизонтальных потоков информации над вертикальными» для большей свободы исследователя и быстрого взаимодействия с другими подразделениями. В таком случае (при прочих равных условиях) предприятию 
Таблица 1. Оценка структур управления

\begin{tabular}{|l|l|l|l|l|l|l|}
\hline & $\mathbf{1}$ & $\mathbf{2}$ & $\mathbf{3}$ & $\mathbf{4}$ & $\mathbf{5}$ & $\mathbf{6}$ \\
\hline Скорость принятия решения & 3 & 2 & 1 & 2 & 2 & 1 \\
\hline Кол-во затрачиваемых ресурсов для решения одной задачи & 3 & 2 & 2 & 2 & 1 & 1 \\
\hline Гибкость и взаимозаменяемость & 2 & 2 & 1 & 2 & 3 & 3 \\
\hline Степень децентрализации & 1 & 1 & 2 & 1 & 2 & 3 \\
\hline $\begin{array}{l}\text { Преобладание горизонтальных потоков информации } \\
\text { над вертикальными }\end{array}$ & 1 & 1 & 2 & 1 & 1 & 3 \\
\hline
\end{tabular}

целесообразно использовать матричную структуру управления.

Однако нужно заметить, что данная методика оценки не учитывает других факторов, таких как:

- наличие других и таких же инновационных задач;

- масштабы предприятия и наличие ресурсов;

- организационная форма предприятия;

- наличие внешних факторов, препятствующих смене организационной структуры управления.

В связи с вышеизложенным можно сказать, что данная методика может помочь определить оптимальную структуру управления, сопоставив реальное положение предприятия и сформированную структуру. Если они не совместимы, следует выбрать ту структуру, которая будет стоять на 2-м месте в рейтинге.

Пути достижения соответствия между инновационными задачами и структурами управления

Организационная структура не является стабильной, она может меняться в зависимости от внешней среды организации. Она строится в соответствии со стратегическими целями организации, определяется характером производственного процесса, особенностями применяемых технологий. Руководитель должен уметь почувствовать необходимость реорганизации и быть готовым к ее проведению.

Изменения в управленческих структурах, связанные с изменениями целей организации, в основном определяются двумя группами факторов. Во-первых, факторами, отражающими необходимость формирования и удержания конкурентных преимуществ на соответствующих целевых рынках, а также развитием научнотехнического прогресса и возможностями использования его результатов для повышения эффективности организации. Во-вторых, воз- можными формами и методами совершенствования самих структур. Такие возможности предусматривают:

- совершенствование структур за счет внутренних резервов, включая децентрализацию, делегирование полномочий на более низкие уровни. Линейные структуры превращаются в более плоские за счет сокращения числа уровней управления с одновременным, как правило, укрупнением функций и сокращением подразделений на одном иерархическом уровне;

- замену механистических структур на адаптивные. Такой переход является наиболее радикальной формой реорганизации структур, но для этого нужен сильный лидер с командой;

- интегрирование (создание) различных форм адаптивных структур внутри механистической структуры, например, путем создания венчурных инновационных отделов, бизнес центров, проектных групп и других;

- формирование структур будущего (модульные и атомистические организации), обеспечивающих общую направленность на массовую экономику при одновременной возможности производства и выпуска нестандартных продуктов, ориентированных на индивидуальный заказ и обслуживание отдельного потребителя. Внедрение этих структур может быть реализовано при переходе от индустриальной фазы организации производства к информационной.

Совершенствование организационной структуры управления приобретает форму поиска альтернативного решения между централизацией и децентрализацией управленческих функций. Желание найти лучшее решение между централизованным и децентрализованным управлением приводит к необходимости создать такую систему управления, которая характеризуется централизованной разработкой оргструктуры предприятия с децентрализованным оперативным управлением.

Такой путь не единственный и не являет- 
ся догмой. В любом случае руководство каждой конкретной организацией должно решить, какой путь подходит именно ему. Так же, например, один из возможных путей к достижению необходимого нам соответствия лежит через применение вышеизложенной методики.

Необходимо отметить, что для каждого отдельно взятого предприятия, в связи с разнообразием решаемых задач, необходимо применять индивидуальный подход к поиску оптимальной организационной структуры управления.

Так оптимальное решение между централизацией и децентрализацией властных функций для одной организации будет идеальным решением. А для другой, имеющей 1-2 проекта это решение будет провальным с любой точки зрения.

В процессе анализа выявлено, что с помощью сформулированных критериев при определенных допущениях можно разработать оптимальную организационную структуру для решения конкретных инновационных задач.
Так же стоит отметить, что помимо указанных в работе структур организационного управления существуют и другие, не затронутые данной работой. В связи с этим исследование может быть расширено, а также, возможно, подкреплено опросами инновационных предприятий.

Сформулированные в данной работе критерии не являются единственно верными, ведь управление инновационным предприятием индивидуально для каждого отдельно взятого предприятия.

У Российской Федерации существует большой потенциал развития в области инноваций в различных областях и сферах человеческой жизни. Однако, лишь грамотное распределение ресурсов, в основном человеческих, позволит России добиться успехов в данном направлении.

Данная работа может помочь наукоемким предприятиям, решающим инновационные задачи, сформулировать оптимальные организационные структуры для решения поставленных задач и помочь в повышении их эффективности.

\section{Библиографический список}

1. Александрова А.И. Структура управления инновационной деятельностью // ПСЭ. 2013. № 3 (47). URL: https://cyberleninka.ru/article/n/struktura-upravleniya-innovatsionnoy-deyatelnostyu.

2. Ансофф И. Новая корпоративная стратегия.- СПб.: Питер Ком, 19999.- 416 с. (Серия «Теория и практика менеджмента»).

3. Гудков И.Б. Методические рекомендации по организации инновационной деятельности на промышленных предприятиях. http://www.gurkov.ru/publ_html/science/1998/1998_1.php

4. Максимов Н.Н. Основные принципы и задачи инновационной деятельности организаций в современных условиях // Молодой ученый. - 2013. - № 10. - C. 344-347. - URL https://moluch.ru/archive/57/7823/

5. Мескон, Майкл. Основы менеджмента: пер. с англ. / М. Мескон, М. Альберт, Ф. Хедоури.- М.: Дело, 2002.701с.: табл. - (Серия «Зарубежный экономический учебник»). - ISBN5-7749-0126-2: 486.

6. Шинкевич О.К.. Курс лекций по дисциплине Основы менеджмента. 2008.

7. Чудесова Г.П. Преобразование организационного управления предприятием методом диверсификации. // Системный анализ в проектировании и управлении: сборник научных трудов XXI Международной научно-практической конференции (Санкт-Петербург, 29-30июня 2017 г.) - 2017. - Т. 2. - С. 5-12 